\title{
Effects of Taping on Wrist Extensor Force and Joint Position Reproduction Sense of Subjects With and Without Lateral Epicondylitis
}

\author{
Won-Hwee Lee, Msc, PT ${ }^{1)}$, OH-Yun Kwon, PhD, PT²), Chung-Hwi Yi, PhD, $\mathrm{PT}^{3)}$, \\ Hye-SEON JeON, PhD, PT ${ }^{3)}$, Sung-Min HA, MsC, PT ${ }^{1)}$ \\ 1) Department of Rehabilitation Therapy, Graduate School, Yonsei University \\ 2) Department of Physical Therapy, Kinetic Ergocise Based on Movement Analysis Laboratory, College \\ of Health Science, Yonsei University: 234 Maiji-ri, Heungup-myon, Wonju-si, Kangwon-do, 220-710 \\ Republic of Korea.TEL: +82 33-760-2721.FAX: +82 33-760-2496, E-mail: kwonoy@yonsei.ac.kr \\ 3) Department of Physical Therapy, College of Health Science, Yonsei University
}

\begin{abstract}
Purpose] The purpose of this study was to assess the effect of taping on wrist extensor force reproduction (FR) and wrist joint position reproduction (JPR) sense in subjects with and without lateral epicondylitis. [Subjects] Thirty workers in an automobile-parts manufacturing company participated: fifteen workers who had experienced pain with lateral epicondylitis and fifteen workers who had no history of lateral epicondylitis. [Methods] Taping was applied on the proximal forearm, starting from the medial, and tracking laterally. This was repeated two or three times. The FR error and JPR error of both groups (with and without lateral epicondylitis) were measured with and without taping. [Results] Without taping, the FR and JPR errors of the lateral epicondylitis group were significantly higher than those of the without lateral epicondylitis group.With taping, the FR error of the lateral epicondylitis group was significantly decreased from $1.24 \mathrm{~kg}$ to $0.49 \mathrm{~kg}$. With taping, the JPR error of the lateral epicondylitis group was significantly decreased from 3.31 to 2.13 degrees. [Conclusion] The lateral epicondylitis group had significantly higher FR and JPR errors. Taping significantly improved force reproduction and joint position reproduction error.
\end{abstract}

Key words: Force reproduction, Joint position reproduction, Taping

(This article was submitted Feb. 22, 2011, and was accepted Apr. 3, 2011)

\section{INTRODUCTION}

Lateral epicondylitis (LE), commonly known as "tennis elbow", is a painful syndrome that occurs in the area of the lateral epicondyle, from which pain radiates proximally or distally depending on the severity of the condition ${ }^{1,2}$. LE is equally common in both genders and usually develops between the ages of 30 and 50 years, although it is four times more frequent in individuals in their $40 \mathrm{~s}^{3)}$. LE affects $3 \%$ of the general population, and this increases to $15 \%$ among people performing certain repetitive manual tasks. LE also substantially affects productivity and $30 \%$ of afflicted workers are absent from work for as long as 12 weeks ${ }^{4}$.

Subjects with LE experience pain during resisted wrist extension, finger extension, and forearm supination ${ }^{5)}$. They also have reduced grip strength and decreased ability to tolerate loading on the extremity, especially while the elbow is extended ${ }^{5}$. The etiology of LE is poorly understood, but the extensor carpi radialis brevis (ECRB) and its origin are believed to be involved in its pathogenesis ${ }^{6}$. Although any one of the wrist or digit extensors may be involved, the
ECRB is implicated more frequently than any other muscle $^{7)}$. The ECRB has a relatively small insertion into the lateral epicondyle, which is a poor biomechanical design for withstanding high loads ${ }^{7}$. Morphological changes in the ECRB may reflect the cumulative effect of mechanical or metabolic overload, decreasing muscle performance in subjects with $\mathrm{LE}^{6}$ ).

Despite its common name, tennis elbow is also an occupational hazard for subjects other than athletes, primarily computer users, cooks, bricklayers, and other occupations that require repeated contraction of the extensor and supinator ${ }^{3,8)}$. LE is the most prevalent work-related musculoskeletal disorder of the elbow ${ }^{2}$. The risk factors include overuse, repetitive movements, training errors, misalignment, flexibility problems, aging, poor circulation, muscular weakness or imbalance, and psychological factors $^{9,10)}$. Previous studies have suggested that LE is caused by a combination of sustained loading and muscle fatigue. Sustained loading may increase strain on the injured soft tissues, promoting muscle fatigue ${ }^{7)}$. A fatigued muscletendon unit is more susceptible to stretch injury, resulting in a predisposition to $\mathrm{LE}^{11)}$. 
Muscle fatigue and strain affect proprioception ${ }^{12-14)}$. Based on the early descriptions by Sherrington and others, the sense of joint position, kinesthesia (perception of active and passive motion), and sense of tension or force are considered submodalities of proprioception ${ }^{15)}$. Joint position sense is one of the most commonly used measures of proprioception ${ }^{16)}$. Determining joint position sense involves measuring the accuracy of joint-angle replication in an open or closed chain environment, which can be done actively or passively ${ }^{15)}$. It is generally accepted that the sense of tension or force actually incorporates a centrally derived sense of effort and a peripherally derived sense of force. The sense of tension or force is commonly assessed using force reproduction (FR) and has been used as a measure of proprioception ${ }^{12)}$. Assessing FR involves the use of a reference force, usually determined as a percentage of a maximal voluntary isometric contraction, and attempting to replicate that force ${ }^{15}$. The muscle spindle and Golgi tendon organs (GTOs) provide information about changes in muscle length and tension, respectively ${ }^{17}$ ). The GTOs are particularly well suited for providing reliable information on muscle force ${ }^{18)}$. Joint position sense originates from peripheral mechanoreceptors located in the skin, muscle, and surrounding joint structures ${ }^{19)}$.Muscle fatigue and strain damage the muscle spindle, decrease motor unit output, and reduce the force-producing capacity of the neuromuscular system $^{12,13,19)}$. Consequently, muscle fatigue surrounding a joint may inhibit the proprioceptive muscle feedback system $^{19)}$. Chronic LE entails decreased proprioception ${ }^{20)}$.

As LE is thought to be primarily an inflammatory condition, most interventions focus on relieving pain and reducing inflammation ${ }^{2}$. Very acute injury may require short-term rest and ice ${ }^{7}$. A wide variety of non-surgical treatments are available, including ultrasound, non-steroidal anti-inflammatory drugs, corticosteroid injections, a forearm brace or orthotics, stretching, eccentric exercise, and taping ${ }^{2,20-24)}$. Oral and topical non-steroidal antiinflammatory drugs and corticosteroid injection may be helpful for breaking the pain cycle ${ }^{25)}$. Smidt compared the efficacy of physiotherapy and corticosteroid injections and found that corticosteroid injection was superior to all other therapies; however, corticosteroid treatment was associated with a high recurrence rate ${ }^{26)}$.

Pienimaki compared the long-term outcomes of progressive exercise and ultrasound, and found that progressive exercise showed beneficial long-term effects in terms of pain alleviation and the ability to work ${ }^{21)}$.Svernlov found that people who participated in strengthening or stretching programs had a statistically significant increase in grip strength ${ }^{23}$ ). Forearm braces significantly decrease muscle activation in the ECRB, but they do not improve muscle fatigue, pain, and pain-free grip strength ${ }^{27-30)}$.

Taping relieves tension at the lateral epicondyle by acting like a secondary muscle attachment site, supports the ligament and capsule of unstable joints by limiting excessive or abnormal anatomical movement, enhances proprioceptive feedback from the limb or joint, and prevents injury to the muscle-tendon unit by compressing the area and limiting movement ${ }^{3,31)}$. In treatment of LE, tape is wrapped tightly around the forearm so that the patient cannot contract the wrist extensors fully ${ }^{3)}$. Taping restricts the movement of the tendon, and reduces stretching during everyday activities.Among the taping application methods, the ring taping method is used commonly and is applied completely around the forearm just below the muscletendon junction ${ }^{31,32)}$.

Although taping improves ankle stability and alleviates patellofemoral pain syndrome, there are no reports on the effect of taping on LE or proprioception in $L^{33-35)}$. Based on the literature, proprioception appears to decrease secondary to $\mathrm{LE}^{36)}$. Therefore, we determined the effect of taping on proprioception in subjects with and without LE. The FR and joint-position reproduction (JPR) tests were conducted to evaluate proprioception. The errors in FR and JPR were calculated to test the accuracy of the subjects' sense of FR and joint position. Increased FR and JPR errors reflect a deficit in proprioception sense. We hypothesized that taping would decrease FR and JPR errors in subjects with LE.

\section{SUBJECTS AND METHODS}

\section{Subjects}

Thirty workers were recruited from an automobile-parts manufacturing company.Fifteen subjects with LE had experienced pain over the lateral epicondyle for at least 6 weeks before the study, and the pain increased during palpation, gripping, and resisted wrist or finger extension. Fifteen age- and sex-matched subjects with no history of LE served as the without LE group. Subjects were excluded if they had any other concomitant bony, neurological, or systemic disease or allergies to adhesive tape, or had undergone any treatment in the previous 6 months. Before the study, the principal investigator explained all of the procedures to the subjects, and all subjects signed an informed consent form which was approved by the Yonsei University Wonju Campus Human Studies Committee. The subject's characteristics are summarized in Table 1.

\section{Methods}

The tape used in this study was non-elastic, 3.8-cm-wide zinc oxide tape (Neoplast Inc) with adhesive backing and high tensile strength. The subjects were asked to rest the elbow in a supported position with the wrist joint extended to contract the ECRB. The tape was placed on the proximal forearm, starting medially, and tracking laterally. This was repeated two or three times ${ }^{34}$.

The principal investigator taped all subjects. The tape was tightened until the subject agreed that it was snug during a contraction of the wrist extensors, but not impeding blood flow. The tape was comfortable when the wrist extensor was relaxed $^{40)}$.

The target force used to calculate FR error was determined using the MP100WSW data acquisition system and a TSD $121 \mathrm{C}$ isometric tensiometer (Biopac Systems).The tensiometer was used to measure the maximum force and FR error $(\mathrm{kg})$ in the wrist extensors. 
Table 1. General characteristics of the subjects

\begin{tabular}{lrcrc}
\hline \multirow{2}{*}{ Variables } & \multicolumn{2}{c}{ With LE group $(\mathrm{n}=15)$} & \multicolumn{2}{c}{ Without LE group $(\mathrm{n}=15)$} \\
\cline { 2 - 5 } & Mean \pm SD & Range & Mean \pm SD & Range \\
\hline Age $(\mathrm{y})$ & $41.9 \pm 6.8$ & $27-52$ & $42.0 \pm 5.2$ & $35-52$ \\
Body mass $(\mathrm{kg})$ & $72.0 \pm 3.7$ & $168-177$ & $72.1 \pm 1.8$ & $168-180$ \\
Height $(\mathrm{cm})$ & $172.1 \pm 2.9$ & $65-78$ & $172.6 \pm 3.5$ & $69-75$ \\
Visual Analog Scale & $5.9 \pm 0.9$ & $4-7$ & & \\
\hline
\end{tabular}

Abbreviations: LE, lateral epicondylitis.

The sampling rate was $1,000 \mathrm{~Hz}$ and a low-pass filter of 5 $\mathrm{Hz}$ was used.The data were digitized using Acqknowledge software (Biopac Systems). The tensiometer was calibrated before each set of measurements.

Subjects were asked to sit with the upper limb at $90^{\circ}$ of shoulder flexion, with the elbow fully extended, forearm pronated, wrist neutral, and the hand grasping a handle connected to the digital tensiometer. Before testing, the digital tensiometer was used to measure the maximum voluntary force (MVF) of the wrist extensor muscles.

Subjects were asked to contract the wrist extensor isometrically and to maintain the target force, which was approximately $20 \%$ of the MVF, for 1 minute, with visual feedback via a computer monitor. After a 1 minute rest, the subject concentrated on the target force with visual feedback for 3 seconds. The principal investigator began the first session by instructing the subject: "Slowly contract the wrist extensor, until I say stop-stop-hold and keep this force in mind for 3 seconds". After a 5 second rest, the principal investigator said: "Now again contract the wrist extensor to the target force and hold it". Five seconds later, the principal investigator said "Now relax the wrist extensor as before". The subject was measured in three trials of the FR test. The FR error $(\mathrm{kg})$ was calculated from the difference between the target and reproduced forces. This test was performed under two different test conditions: without and with taping. The mean value of three trials was used in the data analysis. The greatest FR error was observed for a target force of $30 \%$ MVF during a pilot test, which was also associated with pain in subjects with $\mathrm{LE}^{48}$. To minimize the effects of pain on FR, we selected a target force of $20 \%$ MVF.

To calculate the JPR error, a three-dimensional ultrasonic motion analysis system (CMS-HS, Zebris, Medzintechnik, Germany) was used to measure the wrist joint position angle. Two triple markers were fastened on the forearm and the dorsal surface of the metacarpals with a strap. The measurement sensor, consisting of three microphones facing the three markers, recorded the ultrasound signal. The measured angles were normalized to $0^{\circ}$ relative to the starting or neutral position. The sampling rate was $20 \mathrm{~Hz}$. The collected kinematic data were analyzed using Win-Data software (CMS-HS, Zebris, Medzintechnik, Germany).

The position of the subject's arm was identical to that in FR testing, except that the wrist and finger joints were in a neutral position. A relative reference position of $0^{\circ}$ was defined by the parallel line extending from the forearm to the fifth metacarpal. Using this reference position, all positive values indicate wrist extension and negative values denote wrist flexion.

Subjects were requested to extend the wrist joint and maintain the wrist position under visual feedback via a computer monitor. Target angles of $20^{\circ}, 25^{\circ}$, and $30^{\circ}$ wrist extension were randomly given. The principal investigator began the first session by instructing the subject, "Slowly extend your wrist, until I say stop-stop-hold, and keep this position in mind for 3 seconds". After a 3 second rest, the principal investigator said, "Now return your wrist to the original resting position and keep it there". After 5 second rest in the neutral position, the subject was instructed, "Return to the same position as before and keep that position for 5 seconds". The JPR error was calculated from the mean absolute difference between the target and reproduced angles, neglecting the direction of the error, i.e., whether it was undershoot or overshoot. Three trials were performed for each target angle $\left(20^{\circ}, 25^{\circ}\right.$, and $\left.30^{\circ}\right)$, for a total of nine trials. The mean value of the nine trials was used in the data analysis. This test was performed two different test conditions: without and with taping. Subjects were permitted a 10-minute rest between test conditions, and the test order was randomized to minimize learning and carryover effects.

The independent t-test was used to compare the FR and JPR errors with respect to groups with and without taping. The paired t-test was used to compare the FR and JPR errors with respect to taping in both groups. The level of statistical significance was chosen as $\mathrm{p}<0.05$.

\section{RESULTS}

Without taping, significant differences were found between the FRand JPR errors in the LE and without LE groups $(p<0.01)$. By contrast, with taping, the differences between the FR and JPR errors in the LE and without LE groups were not significant $(\mathrm{p}=0.55,0.61)$ (Tables 2,3$)$.

Tables 4 and 5 compare the FR and JPR error in the LE and without LE groups with and without taping, respectively. The only significant differences were in the LE group $(\mathrm{p}<0.01)$.

\section{DISCUSSION}

Our results demonstrate that without taping, the wrist extensor FR and JPR errors were significantly increased in the LE group compared with the without LE group. Based on these results, the LE group appears to have had decreased 
Table 2. Comparison of FR error by group

\begin{tabular}{llcc}
\hline & Group & FR error $(\mathrm{kg})$ Mean \pm SD & Mean Difference (95\% CI) \\
\hline \multirow{2}{*}{ Without taping } & LE group & $1.24 \pm 0.48$ & $0.76(0.45-1.06)$ \\
& Without LE group & $0.48 \pm 0.31$ & \multirow{2}{*}{$0.06(-0.14-0.26)$} \\
\hline \multirow{2}{*}{ With taping } & LE group & $0.49 \pm 0.32$ & \\
& Without LE group & $0.43 \pm 0.21$ & \\
\hline
\end{tabular}

Abbreviations: CI, confidence interval; LE, lateral epicondylitis; FR, force reproduction.

Table 3. Comparison of JPR error by group

\begin{tabular}{llcc}
\hline & Group & JPR error $\left(^{\circ}\right)$ Mean \pm SD & Mean Difference (95\% CI) \\
\hline \multirow{2}{*}{ Without taping } & LE group & $3.31 \pm 1.24$ & \multirow{2}{*}{$1.43(0.55-2.32)$} \\
& Without LE group & $1.87 \pm 1.11$ & \multirow{2}{*}{$0.18(-0.56-0.92)$} \\
\hline \multirow{2}{*}{ With taping } & LE group & $2.13 \pm 0.86$ & \\
& Without LE group & $1.95 \pm 1.11$ & \\
\hline
\end{tabular}

Abbreviations: JPR, joint position reproduction; LE, lateral epicondylitis.

Table 4. Comparison of FR error by taping

\begin{tabular}{llcc}
\hline Group & Taping & FR error $(\mathrm{kg})$ Mean \pm SD & Mean Difference (95\% CI) \\
\hline \multirow{2}{*}{ LE group } & Without taping & $1.24 \pm 0.48$ & $0.74(0.41-1.07)$ \\
& With taping & $0.49 \pm 0.32$ & $0.04(-0.07-0.16)$ \\
\hline \multirow{2}{*}{ Without LE group } & $\begin{array}{l}\text { Without taping } \\
\text { With taping }\end{array}$ & $0.48 \pm 0.31$ & $0.43 \pm 0.21$ \\
\hline
\end{tabular}

Abbreviations: LE, lateral epicondylitis; FR, force reproduction.

Table 5. Comparison of JPR error by taping

\begin{tabular}{llcc}
\hline Group & Taping & JPR error $\left(^{\circ}\right)$ Mean \pm SD & Mean Difference (95\% CI) \\
\hline \multirow{2}{*}{ LE group } & Without taping & $3.31 \pm 1.24$ & $1.17(0.30-2.03)$ \\
& With taping & $2.13 \pm 0.86$ & \multirow{2}{*}{ Without LE group } \\
Without taping & $1.87 \pm 1.11$ & $-0.08(-0.52-0.35)$ \\
& With taping & $1.95 \pm 1.11$ & \\
\hline
\end{tabular}

Abbreviations: CI, confidence interval; JPR, joint position reproduction; LE, lateral epicondylitis.

proprioception, which may be explained in the following ways.

First, the LE was caused by ECRB muscle strain $^{7)}$. Laboratory studies have shown that muscle strain injuries result in the disruption of muscle fibers near the muscletendon junction ${ }^{37)}$. When the muscle fibers are damaged, spindle discharge levels fall significantly ${ }^{12)}$. If the muscle strain also damaged the tendon, the function of the GTOs decreases. Consequently, muscle strain results in deficits in force and joint position sense.

Second, pain may have affected force perception ${ }^{14)}$. The perception of force is mediated primarily by signals related to central motor command or by sensations originating in peripheral receptors ${ }^{18)}$. Mechanical and physiological reactions of pain might cause damage to muscle tissue. Consequently, pain sensors in the muscles may become hypersensitive ${ }^{37}$. Studies of LE have shown that chronic pain in the neck/shoulder, elbow/forearm, and hand are accompanied by reduced proprioception ${ }^{36)}$.

Third, the ECRB shows morphological changes in patients with LE. Insufficient blood supply may lead to decreased contractile properties and increased vulnerability to high muscular tension ${ }^{6}$. In addition, the elbow ligament and connective tissues in chronic LE undergo degenerative changes at the common origin of the extensor tendons ${ }^{36)}$.

Fourth, LE has been described as a muscle-tendon disease of the wrist extensor due to physical overuse. Physical overuse may involve muscle fatigue, which has been shown to affect proprioception ${ }^{38}$. Muscle fatigue increases the sensitivity of the muscle spindle, resulting in less efficient intra- and inter-muscular coordination and poorer proprioception $^{36)}$.

The reduction in proprioceptive function may be the result of receiving feedback from incorrect body information, dyscontrol in exact body movements, and the addition of greater stress to the muscle and joint. Reduced 
proprioception alters the gait and induces inappropriate joint loading, which may lead to progressive joint degeneration $^{39)}$. Consequently, patients with LE may stress the structures surrounding the wrist joint, which may lead to wrist joint degeneration.

Taping significantly decreased the wrist extensor FR error in the LE group $(p<0.01)$, lowering the mean FR error from 1.24 to $0.49 \mathrm{~kg}$, whereas it decreased the mean FR error from 0.48 to $0.43 \mathrm{~kg}$ in the without LE group. Our results suggest that taping has much greater effect on the FR error in the LE group. The force produced by muscle contraction is perceived via the integration of signals derived from central motor commands and afferent inputs from muscle sensors, and joint and skin mechanosensors. The GTOs are thought to be a primary source of such feedback ${ }^{40)}$. The mechanism underlying the reduction in the FR error after taping is unknown. However, McConnell ${ }^{41}$ ) recommended taping as a therapy to alleviate pain, improve muscle function, and restore functional movement patterns. Recent research demonstrated that the facilitation of proprioceptive cutaneous input via taping helped to improve reaction speed and position awareness ${ }^{42)}$. Therefore, we postulate that taping reduced tension stress in the ECRB and increased cutaneous sense feedback, resulting in a significant decrease in FR error.

In this study, taping had a significant effect on the JPR error. In the LE group, the mean JPR error was $3.31^{\circ}$ before taping and $2.13^{\circ}$ after taping compared with $1.87^{\circ}$ before and $1.95^{\circ}$ after taping in the without LE group. The improvement in wrist joint position sense was due to augmented afferent input via enhanced cutaneous simulation from taping in the LE group. In the without LE group, taping disrupted the joint position sense. Previous studies showed that patellar taping improved the joint position test results in subjects whose prior results were incorrect by $>5^{\circ}$. In contrast, subjects who had a high degree of accuracy $\left(<5^{\circ}\right.$ incorrect) did not benefit from taping $\left.{ }^{43}\right)$. Other studies have shown a $66 \%$ improvement in subjects with poor position sense after applying elastic bandages to the joint; however, the same treatment had no effect on subjects with good position sense ${ }^{44)}$. Taping may enhance feedback information from the muscle spindles, soft tissue, and skin in subjects with $\mathrm{LE}^{33)}$. In contrast, the taping enhanced afferent stimulation may confuse individuals who have inherently good position sense ${ }^{44)}$. The clinical implications of these findings are that poor force sense and joint position sense status can be enhanced by a simple taping technique.

Our study had some limitations. First, taking repeated measures from a single arm makes it difficult to prevent learning and carry-over effects completely. Second, no consensus has been reached concerning the optimum tension for taping this type of injury.

Further studies are required to determine the mechanism underlying the beneficial effects of taping in subjects with LE and to test the long-term effect of taping on proprioception, pain, and dysfunction of the elbow joint in subjects with LE.

\section{REFERENCES}

1) Trudel D, Duley J, Zastrow I, et al.: Rehabilitation for patients with lateral epicondylitis: A systematic review. J Hand Ther, 2004, 17: 243-266.

2) Fedorczyk JM: Tennis elbow: Blending basic science with clinical practice. J Hand Ther. 2006, 19: 146-153.

3) Pecina MM, Bojanic I: Overuse injuries of the musculoskeletal system (2nd ed). Florida: CRC Press, 2004, pp 85-105.

4) Bisset LM, Russell T, Bradley S, et al.: Bilateral sensorimotor abnormalities in unilateral lateral epicondylalgia. Arch Phys Med Rehabil, 2006, 87: 490495.

5) Boyer MI, Hastings H II: Lateral tennis elbow: Is there any science out there? J Shoulder Elbow Surg, 1999, 8: 481-491.

6) Ljung BO, Lieber RL, Friden J: Wrist extensor muscle pathology in lateral epicondylitis. J Hand Surg Br, 1999, 24: 177-183.

7) Wilson A, Boyling JD: Effective management of musculoskeletal injury. London: Churchill Livingstone, 2002. pp 221-245.

8) Noteboom T, Cruver R, Keller J, et al.: Tennis elbow: A review. J Orthop Sports PhysTher, 1994, 19: 357-366.

9) Almekinders LC, Temple JD: Etiology, diagnosis, and treatment of tendonitis: An analysis of the literature. Med Sci Sports Exerc, 1998, 30: 1183-1190.

10) Bongers PM, Kremer AM, TerLaak J: Are psychosocial factors, risk factors for symptoms and signs of the shoulder, elbow, or hand/wrist?: A review of the epidemiological literature. Am J Ind Med, 2002, 41: 315-342.

11) Mair SD, Seaber AV, Glisson RR, et al.: The role of fatigue in susceptibility to acute muscle strain injury. Am J Sports Med, 1996, 24: 137-143.

12) Brockett C, Warren N, Gregory JE, et al.: A comparison of the effects of concentric versus eccentric exercise on force and position sense at the humeral elbow joint. Brain Res, 1997, 771: 251-258.

13) Skinner HB, Wyatt MP, Hodgdon JA, et al.: Effect of fatigue on joint position sense of the knee. J Orthop Res, 1986, 4: 112-118.

14) Proske U, Gregory JE, Morgan DL, et al.: Force matching errors following eccentric exercise. Hum MovSci, 2004, 23: 365-378.

15) Dover G, Powers ME: Reliability of joint position sense and forcereproduction measures during internal and external rotation of the shoulder. J Athl Train, 2003, 38: 304-310.

16) Voight ML, Hardin JA, Blackburn TA, et al.: The effects of muscle fatigue on and the relationship of arm dominance to shoulder proprioception. J Orthop Sports Phys Ther, 1996, 23: 348-352.

17) Schmidt RA, Lee $T$ : Motor Control and Learning: A behavioral emphasis (4th ed). Champaign: Human Kinetics, 1999, pp 4-18

18) Carson RG, Riek S, Shahbazpour N: Central and peripheral mediation of human force sensation following eccentric or concentric contractions. J Physiol, 2002, 539: 913-925.

19) Kwon OY, Choi HS, Yi CH, et al.: The effects of knee and ankle muscles surrounding the knee and ankle joints on one leg static standing balance. $\mathrm{J}$ Phys Ther Sci, 1998, 10: 7-12.

20) Chan HL, Ng GYF: Effects of counterforce forearm bracing on wrist extensor muscles performance. Am J Phys Med Rehabil, 2003, 82: 290-295.

21) Pienimaki $T$, Karinen $P$, Kemila $T$, et al.: Long-term follow-up of conservatively treated chronic tennis elbow patients. A prospective and retrospective analysis. Scand J Rehabil Med, 1998, 30: 159-166.

22) Solveborn SA: Radial epicondylalgia ('tennis elbow'): Treatment with stretching or forearm band. A prospective study with long-term follow-up including range-of-motion measurements. Scand J Med Sci Sports, 1997, 7: 229-237.

23) Svernlov B, Adolfsson L: Non-operative treatment regime including eccentric training for lateral humeral epicondylalgia. Scand J Med Sci Sports, 2001, 11: 328-334.

24) Vicenzino B: Lateral epicondylalgia: A muculoskeletal physiotherapy perspective. Man Ther, 2003, 8: 66-79.

25) Assendelft W, Green S, Buchbinder R, et al.: Tennis elbow. ClinEvid, 2004, 11: $1633-1644$

26) Smidt N, van der Windt DA, Assendelft WJ, et al.: Corticosteroid injections, physiotherapy, or a wait-and-see policy for lateral epicondylitis: a randomized controlled trial. Lancet, 2002, 359: 657-662.

27) Knebel PT, Avery DW, Gebhardt TL, et al.: Effects of the forearm support band on wrist extensor muscle fatigue. J Orthop Sports PhysTher, 1999, 29: $677-685$.

28) Meyer NJ, Pennington $W$, Haines B, et al.: The effect of the forearm support band on forces at the origin of the extensor carpi radialisbrevis: A cadaveric study and review of literature. J Hand Ther, 2002, 15: 179-184.

29) Meyer NJ, Walter F, Haines B, et al.: Modeled evidence of force reduction at the extensor carpi radialisbrevis origin with the forearm support band. $\mathrm{J}$ 
Hand Surg Am, 2003, 28: 279-287.

30) Wuori JL, Overend TJ, Kramer JF, et al.: Strength and pain measures associated with lateral epicondylitis bracing. Arch Phys Med Rehabil, 1998, 79: 832-837.

31) Perrin DH: Athletic taping and bracing (2nd ed). Greensboro: Human Kinetics, 2005. pp91-101

32) Thompson A, Skinner A, Piercy J: Tidy's physiotherapy. 12th ed. London: Butterworth-Heinemann, 1991, pp60-63.

33) Callaghan MJ, Selfe J, McHenry A, et al.: Effects of patellar taping on knee joint proprioception in patients with patellofemoral pain syndrome. Man Ther, 2008, 13: 192-199.

34) Ng GY, Chan HL: The immediate effects of tension of counterforce forearm brace on neuromuscular performance of wrist extensor muscles in subjects with lateral humeral epicondylitis. J Orthop Sports PhysTher, 2004, 34: 7278.

35) Vicenzino B, Brooksbank J, Minto J, et al.: Initial effects of elbow taping on pain-free grip strength and pressure pain threshold. J Orthop Sports PhysTher, 2003, 33: 400-407.

36) Juul-Kristensen B, Lund H, Hansen $\mathrm{K}$, et al.: Poor elbow proprioception in patients with lateral epicondylitis than in healthy controls: A cross-sectional study. J Shoulder Elbow Surg, 2008, 17: 72S-81S

37) van Tulder M, Malmivaara A, Koes B: Repetitive strain injury. Lancet, 2007, 369: $1815-1822$

38) Walsh LD, Hesse CW, Morgan DL, et al.: Human forearm position sense after fatigue of elbow flexor muscles. J Physiol, 2004, 558: 705-715.

39) Barrett DS, Cobb AG, Bentley G: Joint proprioception in normal, osteoarthritic and replaced knees. J Bone Joint Surg Br, 1991, 73: 53-56.

40) Nicolas G, Marchand-Pauvert V, Lasserre V, et al.: Perception of nonvoluntary brief contractions in normal subjects and in a deafferented patient. Exp Brain Res, 2005, 161: 166-179.

41) McConnell J: A novel approach to pain relief pre-therapeutic exercise. J Sci Med Sport, 2000, 3: 325-334.

42) Morrissey D: Proprioceptive shoulder taping. Journal of Bodywork and Movement Therapies, 2000, 4: 189-194.

43) Callaghan MJ, Selfe J, Bagley PJ, et al.: The effect of patellar taping on knee joint proprioception. J Athl Train. 2002, 37: 19-24.

44) Perlau R, Frank C, Fick G: The effect of elastic bandage on human knee proprioception in the uninjured population. Am J Sports Med. 1995, 23: 251255 . 